\title{
SETTING A CITY STRATEGY FOR LOW CARBON EMISSIONS: THE ROLE OF ELECTRIC VEHICLES, RENEWABLE ENERGY AND ENERGY EFFICIENCY
}

\author{
J. PRATA ${ }^{1}$, E. ARSENIO ${ }^{2}$ \& J.P. PONTES ${ }^{3}$ \\ ${ }^{1}$ Foundation for Science and Technology, Portugal. \\ ${ }^{2}$ LNEC I.P., Department of Transport, Portugal. \\ ${ }^{3}$ ISEG, Lisboa School of Economics and Management, Portugal.
}

\begin{abstract}
One of the European policy objectives, as envisaged by the EC Transport White Paper, is to reduce Europe's dependence on imported oil and to cut greenhouse gas emission from transport by $20 \%$ by 2030 and by $70 \%$ until 2050 (with respect to 2008 levels). For achieving this goal, the role of integrated energy and urban mobility systems are explored as part of a city's strategy towards sustainability (2011-2020). For developing future scenarios, we used best practice foresight analysis methods, where the desirable future relates to European policy goals. In this research, we adapt the extended metabolism model of a city developed by Newman (1999) and the material and energy flow accounting by Sheerin (2002) to assess the future role of electric vehicles, renewable energy (RE) use for mobility needs and energy efficiency increases for households living in the city of Aveiro, a medium-sized city of 78,450 inhabitants in Portugal. The social costs of carbon related to alternative vehicle technologies (electric vehicles) are assessed, along with the integration of RE. Several energy sources were considered: hydric, wind, solar (thermic and photovoltaic) and solid waste (incineration and biogas). A Life-Cycle Assessment analysis was performed for this estimation, where a share of 56\% of RE was assumed to be achieved until 2020. It was found that each battery electric vehicle and the use of RE has an external cost associated with climate change of $0.032 € / 1000 \mathrm{pkm}$ in 2011 and $0.012 € / 1000 \mathrm{pkm}$ in 2020 . For the city of Aveiro, this represents an external cost of $7094 €$ in terms of $\mathrm{CO}_{2}$ related emissions in 2020. If all conventional fuelled vehicles were replaced by electric bicycles, an energy reduction of $98.1 \%$ and an emission reduction of $3893 \mathrm{~kg} \mathrm{CO}_{2 \mathrm{eq}}$ per year (avoided $\mathrm{CO}_{2 \mathrm{eq}}$ external costs of $5.96 \mathrm{M} €$ ) could be achieved.
\end{abstract}

Keywords: battery electric vehicles and electric bicycles, renewable energy, energy efficiency, European transport policy and planning, $\mathrm{CO}_{2}$ emissions, climate change costs, traffic calming measures.

\section{INTRODUCTION}

Cities have an important role to accommodate for European policies because these represent centres of high-energy consumption, waste creation along with $\mathrm{CO}_{2}$ free emissions. European policies aim to a resource-efficient and low carbon economy reduction of fuel consumption along with the dependence of European oil imports [1,2]. The EC Transport White Paper aims to reduce $60 \%$ of greenhouse gas emission, until 2050, drawing 10 goals for a competitive and resource efficient transport systems [1]. This will require a future technological shift, assuming the EU is committed to its 2050 ambitions to decarbonise the electricity and transport sector [1,3]. Conventionallyfuelled cars are envisaged to be reduced by half until 2030 and fully replaced by battery electric vehicles (BEVs) until 2050 [1]. As such, environmental and energy-related issues, along with economic and technology led factors, are crucial for cities to converge towards sustainability. Around 70-80\% of world's population live in the cities [4] and around $27 \%$ of world's energy consumption (8677 Mtoe) is used in the transport sector and represents around $25 \%$ of global $\mathrm{CO}_{2}$ emissions (30,326 Mt), in 2010 [5]. This paper adapts the extended metabolism model of a city developed by Newman [6] and the material and energy flow accounting by Sheerin [7] to assess the future role of electric vehicles (BEVs and electric bicycles, EBs), and renewable energy (RE) as key inputs for sustainable mobility patterns in the city of Aveiro. The focus of this research is investigate the future role of electric 
vehicles (EVs), RE and energy efficiency (EE) as an integrated energy system to supply the energetic needs for households' daily mobility in 2020, considering the usual daily functional trips (home to work/school). The remainder of this paper is organized as follows. Section 2 presents the state of the art on the sustainable mobility paradigm and on urban metabolism approaches, including a review of measures to facilitate bicycle use, especially traffic-calmed areas. Section 3 develops the case study for the Portuguese city of Aveiro. Finally, Section 4 presents the conclusion outlines and future research.

\section{SUSTAINABILITY MOBILITY AND URBAN METABOLISM APPROACHES}

Sustainable transport could be defined as a balance between transport activities and the resources used to meet the needs of the present generation without compromising the capacity of future generations [8]. Thus, sustainable mobility requires a non-decreasing accessibility and the consideration of intra and intergenerational issues. Technology development, use of public transport, cycling and walking along with promoting transport integration/intermodality represent fundamental keys to achieve sustainable consumption patterns. Sustainable transport planning is being a challenge of urban planners for long due to the complexity of the land use and transport interactions. Therefore, the city strategy shall be a compromise of socio-economic, environment and energy issues and explore the emerging role of greener technologies. Following Banister [4], the concept of sustainable mobility provides an alternative paradigm where the city can be represented through its complex system based on the link between land use and transport. The pathways towards sustainable mobility city futures would require that transition models would overcome current barriers (replacing of old vehicles technologies) such as: (i) technology components and vehicles; (ii) physical infrastructure and (iii) institutional infrastructure [9]. The focus of this research is on emerging vehicle technologies based on BEVs and EBs, which are explored to address functional daily trips in the city of Aveiro. The future of these technologies will depend on the development of: (i) charging infrastructures; (ii) changes in mobility patterns (intermodality systems and car-sharing); (iii) developments in the global car manufacturing with emphasis to development of batteries and electric-propulsion; (iv) trends in energy prices; (v) the improvement of the electricity sector and (vi) policies that stimulate the electric mobility [10].

\subsection{Sustainability concepts: background}

Over the last decades, several concepts have been developed around the topic of sustainability and city planning such as: sustainable cities, urban sustainability, green cities, compact cities, resilient cities, urban sustainable development, amongst others. The sustainable city concept, based on the idea of a self-sufficient system, is in practice very difficult to achieve [11,12]. The goal of urban sustainability can be defined as the 'reduction in the use of natural resources and production of wastes of a city-region while simultaneously improving its liveability, in terms of social amenity and health, so that it can better fit within the capacities of the local, regional and global ecosystems' [6]. Following Jim [13], increasing urban sustainability leads to a greener city, which is characterized by: (i) high-quality green spaces; (ii) efficient planning and management and (iii) a healthy environment for humans, vegetation and wild-life population. The compact-city model allows more cost-efficient transport systems in cities. In spite of that, the compact city is associated with other drawbacks such as noise, poor air quality, lack of green spaces and higher risk of disasters, and could pose a paradox for the sustainability concept [14]. Extrapolating the concept of resilience to the urban context, Holling [15] suggests 'the persistence of relationships within a system' and 'the ability of these systems to absorb changes of state variables, driving variables, and parameters, and still persist' [16]. 
In the extreme equilibrium view, resilience is defined as the ability of systems (cities), when exposed to harmful events, to return back to their equilibrium point whereas under the non-equilibrium paradigm, resilience is the ability of a city system to adapt and adjust to changing internal or external processes [17]. Following Shen et al. [18], urban sustainability indicators refer to four important dimensions: (i) environmental, such as freshwater, wastewater, air quality, noise pollution, sustainable land use, waste generation and management and greener transportation systems; (ii) economic, such as consumption and production patterns, economic development and finance; (iii) social, such as energy and water access, education, health, safety, transportation, adequate housing, shelter, culture, green places, social integration and support disadvantageous groups; and (iv) governance, such as efficient governance, participation and civic engagement, sustainable management of the authorities and businesses.

\subsection{Building an urban metabolism methodological approach}

Abel Wolman developed the concept of urban metabolism with a model accounting for the material inputs and outputs in an urban system [19]. Urban metabolism can be represented as the global sum of all processes that occur in cities, which can be technical and socioeconomic changes and metabolic balances related to growth promotion, energy production and waste elimination [20,21]. Odum's Emergy and the mass balance accounting can characterize the urban metabolism. Howard T. Odum developed the concept of emergy (emJ), which represents energy quality. The quality of energy cannot be expressed by energy units, as cal, btu's, kWh, J, etc. [22]. Although there are several studies using Odum's emergy methods for the case of ecological systems, few applications have been made to the case of urban planning due to its complexity [20,23]. In this research, we apply the energy-materials flux approach and can be represented by several quantification methods such as material flow analysis (MFA) and life cycle assessment, allowing the quantification of energy and material consumption.

2.2.1 Urban metabolism approach: energy-materials flux approach

The MFA was first applied for the case of local industrial processes (industrial metabolism) [24] and in the 1990s, it was extended to the national level such as in Austria and Japan [25]. To our knowledge, the MFA was formerly applied in Portugal by Niza et al. [26] to study the urban metabolism for the city of Lisbon. The urban system can be considered as an open steady system because it is possible to account for (i) the energy input that is converted to an output of pollutants (if the energy source is entirely renewable there are no emissions); (ii) the material inputs that are converted into waste outputs and other effluents; (iii) the imports and exports, stocks, that represent externalities associated with the socio-economic metabolism $[7,23,24]$. As such, the reintegration of output flows into inputs than re-enter in the urban system will increase city's efficiency. The extended metabolism model (EMM) of a city developed by Newman [6] used in this research was based on the experience of the Human Settlements Panels in the Australia State of the Environment Reporting process, which include the dynamics (transportation, economic and cultural priorities) and liveability in these settlements (health, employment, income, education, housing, leisure activities, accessibility, urban design quality and community). In addition, we have used the material and energy flow accounting by Sheerin [7] for the case study analysis. The EMM is similar to the MFA and it can be applied to: (i) industry; (ii) household; (iii) comparison between different cities and (iv) firms [27]. On the other hand, the MFA approach comprises economic data providing an economic interpretation about the region [7]. 


\subsection{Measures to facilitate electric bicycle use}

Although current mobility patterns in most Portuguese cities are car oriented, city decision makers are starting to be aware of the benefits of shifting to more sustainable modes such as walking and cycling as a means to reduce congestion, air pollution and improve quality of life. Therefore, the development of a city strategy normally comprises an action plan with a set of measures to facilitate the use of public transport along with walking and cycling. Traffic calming schemes are normally recommended for reducing motorized traffic speed, improving traffic safety, increasing liveability and protecting the environment [28]. The implementation of 'Zones 30' where vehicle speeds are lower than $30 \mathrm{~km} / \mathrm{h}$ could prevent the occurrence of accidents and their consequences [29]. These zones shall be signalized with speed limits and accompanied by other speed reduction measures (examples are road humps, raised junctions, speed cushions, horizontal deflections, mini-roundabouts, bends and reductions in the width of carriage ways), along with speed control measures [29]. Considering the emerging electric vehicle technologies such as EBs, it is foreseen and desirable the implementation of traffic calming measures along with the diffusion and market enlargement of this technology at the city level.

\subsection{External costs related to climate change impacts}

The social cost of carbon is the sum of internal and external costs. Internal costs are associated with users' direct expenses such as fuel consumption, maintenance, insurance, taxes and depreciation of technology over time and staff and infrastructure [30]. Externalities or external costs (ExC) arise from production effects or other consumption activities that are not directly included on the market, which has side effects to the society and imply a social cost. The presence of non-internalized externalities can be considered as a source of economic inefficiency as transport prices do not reflect social marginal costs [31]. The state of the art on transport economics usually categorizes externalities into various specific groups such as climate change, air quality, accidents (costs that are external), noise, soil pollution, water pollution, biodiversity, visual impact, upstream-downstream effects related to the built of infrastructures, vehicles, fuel production and congestion effects. In this research, we use as performance indicator of each long-term scenario the external costs of $\mathrm{CO}_{2}$ emissions, noting that the city of Aveiro strategy aims to reduce carbon emissions from transport until 2020.

\section{THE CASE STUDY AT THE CITY OF AVEIRO}

As mentioned in Section 2, this research adopted the MFA by Sheerin [7] and the EMM approach by Newman [6] to the city of Aveiro, a medium sized city in Portugal. This had considered the collection of several types of data, such as transport and mobility, energy and socioeconomic variables (household size, age structure, etc.), also useful to build long-term scenarios (2020). The reference situation data refer to 2011. The methodology comprised the following steps:

a. Development of future long-term scenarios based on prospective exercise, considering the integration of bicycle infrastructures and the internalization of ExC avoided (climate change) in the economic system.

b. Application of the MFA to analyse energy and materials flows (inputs and outputs). The energy sources (inputs) were identified for mobility needs using electricity, natural gas and fossil fuels. Inputs for basic human needs were water, food, waste and pollutants $\left(\mathrm{CO}_{2}\right)$.

c. Analysis of the potential energy mix available for future household mobility needs until the 2020 horizon. The EE was analysed that could be achieved from the integration of RE and EVs for 
daily functional trips. Energy inputs per household considered the use of one microturbine (97 $\mathrm{kW}$ ) [32], use of wind energy turbine (5kW - viable for each 10 households), solar energy (two PV $(0.3 \mathrm{~kW})$ and thermal panels per household [33] and solid waste (incineration and burning of biogas [34]).

d. Characterization of typical household profiles regarding key patterns of consumer behaviour (mobility centred).

e. Analysis of traffic calming measures costs and climate change costs.

\subsection{Development of future long-term scenarios: prospective exercise}

As mentioned before, the data used in this research comprised an integrated set of energy, transport and socio-economic useful to the development of the scenarios for the city of Aveiro [35-38]. Figure 1 shows the key methodological steps of the prospective methodology, as follows: (i) characterization of the current situation in terms of the global energy consumption, mobility patterns and inherent $\mathrm{CO}_{2}$ emissions (reference year 2011); (ii) identification of the predetermined elements, wildcards and crucial uncertainties (literature review of European and national studies); (iii) comprehensive analysis of 'possible' versus 'desirable futures'; (iv) strategy (convergence for long-term goals set by the EC white paper).

Predetermined elements are those variables that are expected to change and their range of variation can be predicted in a great extent [39]. The literature review analysis conducted to the following predetermined elements: (i) climate change issues (continued concern for global warming); (ii) costs of fossil fuels (increase); (iii) investment in RE (increase); (iv) energy intensity (decrease); (v) new ICTs (promoting efficiency in mobility); (vi) technology development (higher levels of efficiency on transport); (vii) charging stations (ensure electricity for higher demand); (viii) integration of bicycle infrastructures and traffic calming measures (to provide safety circulation for users: between house-work/school-house) and (ix) reduce the need to travel (internet shopping, eLearning classes, work through home). Crucial uncertainties are those which define the system dynamics and are somehow controllable, but there is no absolute certainty about the implicit mechanisms of transmission. Therefore, the changes that one uncertain element can induce in the future need to be continuously monitored [40]. The European and national analysis at this level allows to the following crucial uncertainties: (i) EU support for cohesion and development; (ii) the Portuguese economy; (iii) boosting of secondary economic sector; (iv) society behaviour and the acceptability of emerging technologies; ( $v$ ) potential integration of EVs; (vi) electric car sharing and (vii) cost of electricity. Wild cards are events that correspond to discontinuities in the system and are associated with a low

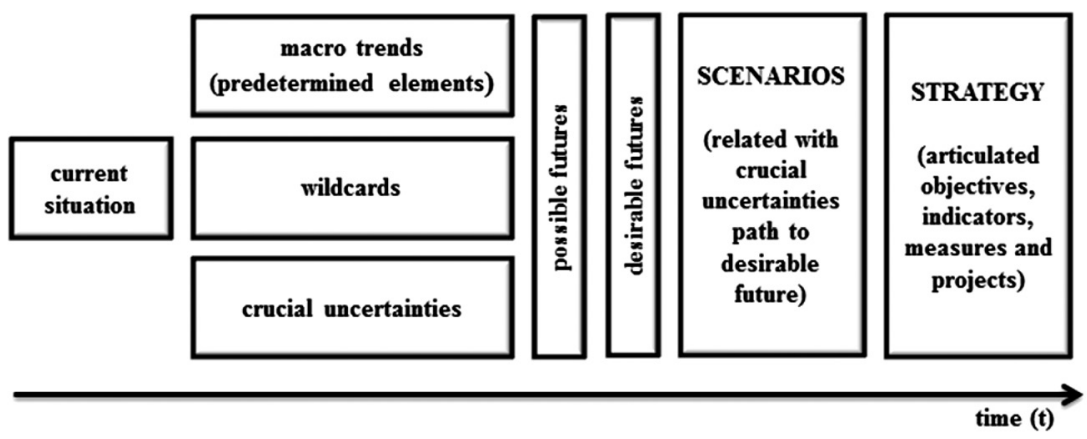

Figure 1: Methodological steps in the prospective exercise scenario. 
probability of occurrence, high impacts and unexpected outcomes [41]. These wild cards are as follows: (i) terrorism and security threats; (ii) natural disasters (particular focus on those related with climate change); (iii) environmental disasters and (iv) collapse of the European economic system. The development of long-term scenarios will conduct to a set of possible futures considering the crucial uncertainties previous referred.

\subsection{Characterization of the city of Aveiro: socio-economic and mobility indicators}

Aveiro is a medium-sized city of 78,450 inhabitants located in the sub-region of Baixo Vouga, of the Centro Region in Portugal. Considering the most recent available statistical data (INE, 2012), 31,142 households are distributed by 14 parishes. Their household structure is as follows: $23.4 \%$ (1 person); $32.7 \%$ (2 persons); $22.5 \%$ (3 persons); $15.9 \%$ (4 persons) and 5.5\% (5 or more persons) $[35,36]$. Figure 2 presents a synthesis of the resident population and employment indicators. Esgueira is the parish with the highest population as residents.

The daily movements of $61.6 \%$ of the Portuguese population are made by car (17.9\% of people use it as passenger, whereas $43.7 \%$ do it as driver [36]). The same mobility patterns are replicated for the city of Aveiro. It was found that most of the students under 15 years of age whom travel to school use their parent's car as a passenger in their daily trips. In line with this indicator, $17.9 \%$ of drivers leave children at school as part of their commuting trips to work. These drivers are members of households with three or more people, which have at least one person aged below 15 years. The second economic sector of Aveiro is exporter, which represents the export 'motor' for the urban economy and where efficiency targets might deserve more allocation of resources. Energy intensity relative to GVA $(\mathrm{kWh} / €)$ is as follows: $0.46 \mathrm{kWh} / €$ (primary sector); $0.82 \mathrm{kWh} / €$ (secondary sector) and $0.21 \mathrm{kWh} / €$ (tertiary sector). As such, the tertiary sector is the one that needs lower energy inputs to produce the same amount of output, ceteris paribus. Since the secondary sector is the exporter, we must conclude that this economic sector is the one that deserves more attention for increasing EE in relation to GVA.

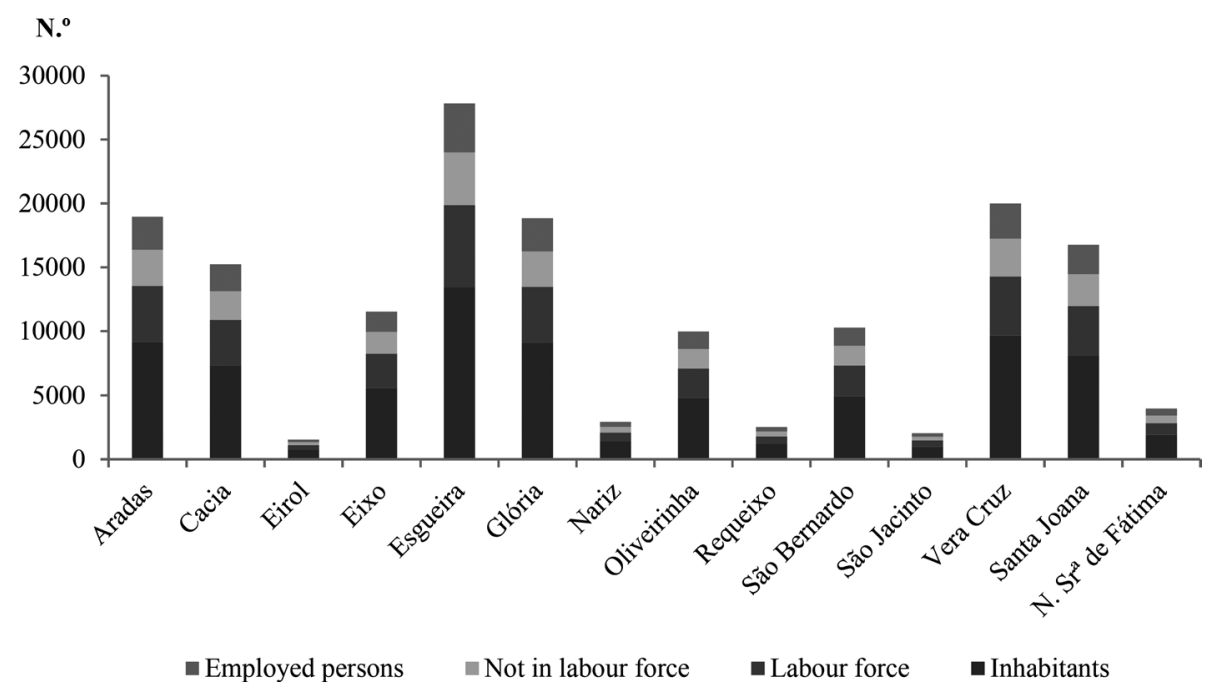

Figure 2: Population and employment indicators for the city of Aveiro [36]. 


\subsection{Material and energy flux analysis}

The analysis used an integrated data collection of energy consumption, transport, solid-waste production and treatment, water and food consumption data for the city of Aveiro [35,36,42-44]. The material and energy flux analysis for the city of Aveiro considered a typical household, which was found to have a size of 2.5 persons and 1.25 motorized vehicles [36]. This research used the sustainability potential concept, which is associated with the lowest possible energy and resources' consumption. It is associated with producing the minimum waste, water effluents and air pollutants, treating and managing these outputs in the most efficient way, valuing these outputs whenever possible, allow their reintegration in the system (as energy or materials) and maximize the production of energy using renewable resources whenever this option represents economic advantages. Further details of the methodology can be found elsewhere $[39,45]$. Table 1 shows the results of the MFA for the city of Aveiro for the reference year 2011 (current situation for long-term scenarios), having as key output the equivalent $\mathrm{CO}_{2}$ emissions.

To quantify the desirable future, the sustainability potential of the city of Aveiro was considered, where each household was assumed to choose different RE options for electricity generation, improving EE and for adopting emerging vehicles technologies -BEVs, having the 2020 horizon. The material inputs (food, water and waste) were assumed the same for all the city households in the analysis. However, the output related with $\mathrm{CO}_{2}$ emissions changed according to each type of the greener technologies to be introduced. One of these greener technologies was the introduction of BEV's, a technological measure in line with the European transport policy [32,35-42-44]. Table 2 (desirable future of long-term scenario) presents the results regarding the potential MFA for Aveiro and the output as equivalent $\mathrm{CO}_{2}$ emissions for 2020, having as reference year 2011. From Table 2, it is found that the integration of RE will represent a share of $56 \%$ in the potential electricity production in 2020. The contribution of each RE source (\%) for energy production is there described. The analysis considered the emissions along the entire chain of production and usage of vehicles - the well-to-wheel (WtW) analysis including incorporation of renewables (range of $\mathrm{gCO}_{2} / \mathrm{kWh}$ ). The typical consumption for a BEV was $49 \mathrm{MJ} / 100 \mathrm{~km}$ and the value for a gasoline internal combustion

Table 1: Material and energy flux analysis for Aveiro.

\begin{tabular}{|c|c|c|c|}
\hline Description & $\begin{array}{c}\text { Quantity (kg.year-1 } \\
\left.\text { or kWh year }{ }^{-1}\right)\end{array}$ & End-use & $\begin{array}{c}\text { Emissions } \\
\left(\mathrm{kg} \mathrm{CO}_{2 \text { eq }} \cdot \text { year }^{-1}\right)\end{array}$ \\
\hline Food (M) & 2349 & \multirow{4}{*}{ Stock in. } & NA \\
\hline Electricity (E) & 3594 & & 1581 \\
\hline Natural gas (E) & 2363 & & 738 \\
\hline Fuel transportation $(\mathrm{E})$ & 9929 & & 3972 \\
\hline \multirow{2}{*}{ Water $(\mathrm{M})^{*}$} & 241,423 & Supply in. & NA \\
\hline & 241,423 & Treatment & NA \\
\hline Waste (M) & 1021 & Landfill out. & 182 \\
\hline Total & \multicolumn{2}{|c|}{$(E)=15,886 ;(M)=3370$} & $\mathrm{GE}=6472$ \\
\hline
\end{tabular}

NA = Not available (negligible); in. = input; out. = output (treatment considered); $(\mathrm{M})=$ material flux; $(E)=$ material flux; *after water treatment, it was assumed that this will be available for consumption again; thus it will not be considered in the sum; $\mathrm{GE}=$ global emissions. 
Table 2: Material and energy flux analysis for Aveiro for 2020.

\begin{tabular}{|c|c|c|c|c|}
\hline \multicolumn{2}{|l|}{ Description } & \multirow{2}{*}{\multicolumn{2}{|c|}{$\begin{array}{l}\begin{array}{l}\text { Quantity }\left(\mathrm{kg} . \mathrm{ano}^{-1}\right. \\
\left.\text { or kWh } \mathrm{ano}^{-1}\right)\end{array} \\
23(2 \%)\end{array}$}} & \multirow{2}{*}{$\begin{array}{c}\begin{array}{c}\text { Emissions } \\
\left(\mathrm{kg} \mathrm{CO}_{2 \mathrm{eq}} \cdot \mathrm{ano}^{-1}\right)\end{array} \\
-10\end{array}$} \\
\hline & Water supply & & & \\
\hline Electricity & Solar PV & $1046(52 \%)$ & & -460 \\
\hline generated by & Wind turbine & $204(10 \%)$ & & -90 \\
\hline \multirow[t]{2}{*}{$\mathrm{RE}(\mathrm{E})$} & Waste incineration & $428(21 \%)$ & & -547 \\
\hline & Biogas & $312(15 \%)$ & Stock in. & 57 \\
\hline \multicolumn{2}{|c|}{ Electricity needs to supply (E) } & 1582 & & 696 \\
\hline \multicolumn{2}{|c|}{ Electricity needs for BEV (E) } & 2561 & & $(* *)-2544$ \\
\hline \multicolumn{2}{|c|}{ Natural gas (E) } & 1796 & & 561 \\
\hline \multicolumn{2}{|c|}{ Solar thermal (E) } & 567 & & -177 \\
\hline \multicolumn{2}{|l|}{ Waste (M) } & 128 & Landfill out. & NA \\
\hline \multicolumn{2}{|c|}{ Waste collection $(\mathrm{M}) *$} & 215 & Treatment out. & NA \\
\hline \multicolumn{2}{|l|}{ Total } & $(E)=8519$ & $\mathrm{GE}=27$ & $\mathrm{EA}=3828$ \\
\hline
\end{tabular}

$\mathrm{EA}=$ emissions avoided; $* *$ Emission of $1428 \mathrm{~kg} \mathrm{CO}_{2 \mathrm{eq}} \cdot \mathrm{ano}^{-1}$ associated with electricity generation.

engine vehicles (ICEV - 1.3GDI Turbo vehicle) was $190 \mathrm{MJ} / 100 \mathrm{~km}$ [46]. In 2010, BEVs emitted $76 \mathrm{gCO}_{2} / \mathrm{km}(\mathrm{WtW})$, whereas a typical $1.3 \mathrm{GDI}$ Turbo vehicle emitted $184 \mathrm{gCO}_{2} / \mathrm{km}(\mathrm{WtW})$. Assuming a full replacement of ICEVs by BEVs until 2020, it was found that BEVs would promote $74.2 \%$ of EE in the mobility daily needs (functional trips). These BEVs would be responsible for $64.0 \%$ reduction of $\mathrm{CO}_{2}$ emissions related to mobility. Considering the integrated energy system (mobility and energy household needs using RE sources), it would be $46.4 \%$ more efficient and $61.8 \%$ greener than for the reference year used in the analysis.

\subsection{Characterization of typical household profiles}

Table 3 shows the energy intensity of different household profiles for the city of Aveiro for 2011 and 2020. An integrated socio-economic data and the previous household consumptions for the city of Aveiro were used to determine the energy intensity. It was assumed that each household contained at least one active member in the labour force. The household income data were based on the data provided by the CCDR-Centro [35]. From Table 3, it can be found that the integration of RE and BEVs as described in Section 3.3 would promote a decrease of around 50\% in energy intensity for each household profile.

The integrated energy system of RE sources could provide a total of $2.6 \mathrm{MWh} /$ household year. This value represents $26.0 \%$ of the actual households' needs for daily functional trips and it would provide $100.0 \%$ of the 2020 's energy mobility needs, avoiding around 1.3 tonnes $\mathrm{CO}_{2} /$ household year. It shall be noted that if all conventional fuelled vehicles were replaced by EBs, it could represent an energy reduction of $98.1 \%$ and an emission reduction of $3893 \mathrm{~kg} \mathrm{CO}_{2 \mathrm{eq}}$ per year, having the year 2011 as reference. 
Table 3: Energy intensity (kWh/€) for different household profiles.

\begin{tabular}{lcccc}
\hline & \multicolumn{4}{c}{ Energy intensity (kWh/€) } \\
\cline { 2 - 5 } $\begin{array}{l}\text { Household size (\% of the city } \\
\text { population) }\end{array}$ & 1 & 2 & 1 & 2 \\
\cline { 2 - 5 } & 6.0 & - & 3.0 & - \\
1 person $(23.4 \%)$ & 12.1 & 6.0 & 5.9 & 3.0 \\
2 persons (32.7\%) & 18.1 & 9.1 & 8.9 & 4.4 \\
3 persons $(22.5 \%)$ & 24.2 & 12.1 & 11.8 & 5.9 \\
4 persons $(15.9 \%) *$ & &
\end{tabular}

-It is not possible to have two employees if the size of family is one person.

*If the size of the family is constituted by three or four persons, it was assumed one or two persons with age under than 15 years, since it represents $39.4 \%$ and $35.2 \%$ of population that family size.

**For households size higher than four persons, the energy intensity was not compute and represents $5.5 \%$ of population.

\subsection{Additional planning measures}

The municipality of Aveiro registered, in 2011, a total of 2719 road accidents with victims as follows: (i) 69 fatalities; (ii) 131 serious injuries and (iii) 3293 with light injuries. Around $65.5 \%$ (1780) of those road accidents occurred within the city and involved 30 victims (13 were pedestrians) and 63 were seriously injured [47]. Considering the social dimension of the road safety problem at the city of Aveiro and noting that $50 \%$ of the students aged $<15$ years will use electric bikes for their daily trips to school until 2020 (long-term scenario), it is assumed the implementation of traffic calming measures and other complementary awareness and information actions for preventing road accidents. The Dutch practices [28], for example, comprise success cases on the implementation of $30 \mathrm{~km} / \mathrm{h}$ zones using low-cost measures such as traffic calming measures at residential areas through gateway/entrances, street space design (for the desirable behaviour of users) and speed reducing measures at critical junctions. Indicative costs of traffic calming measures (road humps, rumble devices, chicanes, vehicle activated signs and roundabouts) can be found in the literature [29].

\subsection{Estimation of external costs related to climate change}

Considering the literature review, Table 4 shows the external costs related to carbon emissions for the case of passenger transport and electricity production. The case study estimated the external costs for the long-term scenario associated with the full replacement of conventionally fuelled vehicles with electric vehicles and RE technologies using the values of the CE/INFRAS/ISI and EC methodology, respectively [48]. In 2011, each BEV has an external cost associated with climate change of $0.032 € / 1000 \mathrm{pkm}$, whereas in 2020 this cost is reduced to $0.012 € / 1000 \mathrm{pkm}$. For the city of Aveiro, this represents an external cost of $7094 €$ in terms of $\mathrm{CO}_{2}$ related emissions in 2020 . If all conventional fuelled vehicles were replaced by EBs, an energy reduction of $98.1 \%$ and an 
Table 4: Climate change costs for passenger transport and electricity production.

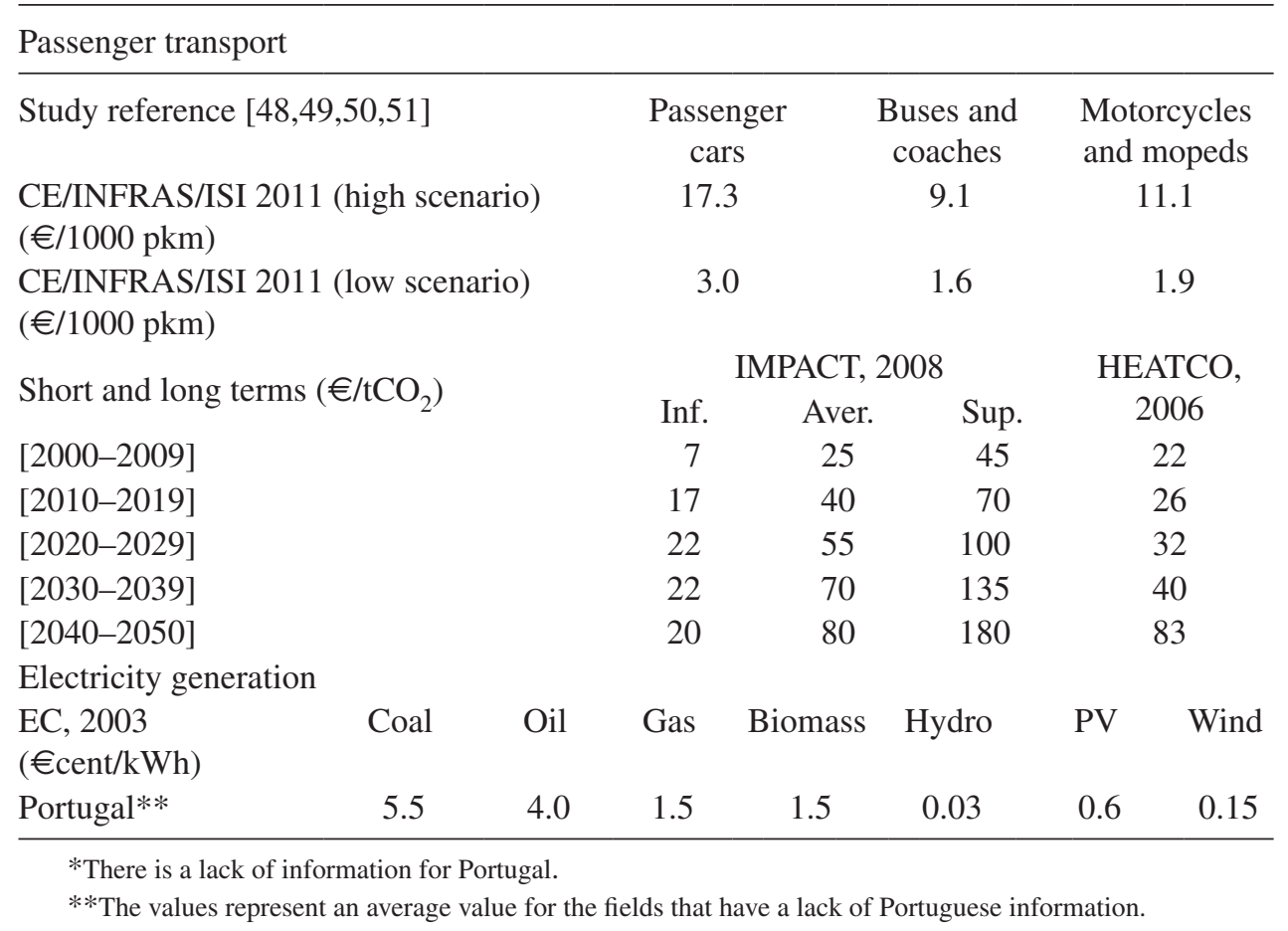

emission reduction of $3893 \mathrm{~kg} \mathrm{CO}_{2 \mathrm{eq}}$ per year (avoided $\mathrm{CO}_{2 \mathrm{eq}}$ external costs of $5.96 \mathrm{M} €$ ) could be achieved. Assuming that $50 \%$ of students aged less than 15 years old will shift from car (parent's car as passenger) to EBs in their daily trips to school (average trip length of $5 \mathrm{~km}$ per day) during 5 days per week each year (10 months per year, excluding holiday time), 38,559 € could be avoided as external costs associated with climate change.

\section{CONCLUSIONS}

Considering the research methodology, a 56\% share of RE was assumed to be achieved until 2020 to meet the city of Aveiro mobility needs. This is in line with the Portuguese investment on electricity generation through wind, hydric and solar sources. Assuming a full replacement of ICEVs by BEVs until 2020, it was found that BEVs would promote $74.2 \%$ of EE in the mobility daily needs (functional trips). These BEVs would be responsible for $64.0 \%$ reduction of $\mathrm{CO}_{2}$ emissions related to mobility until 2020 in comparison with 2011. By 2020, the external costs related to climate change as a result of integrating electric vehicles and RE would represent $0.012 \%$ of the ICEVs external costs in 2011 (savings of around $5.96 \mathrm{M} €$ ). Assuming that $50 \%$ of students aged $<15$ years old will shift from using parent's car as passenger to EBs in their daily trips to school, around 38,559 $€ /$ year could be avoided as external costs associated with climate change. In 2020, each EB user would emit $109 \mathrm{~kg} \mathrm{CO}_{2} /$ year (average distance traveller/year is $1000 \mathrm{~km}$ ). Research results demonstrate the potential role of integrated energy and mobility systems at the city of Aveiro, namely regarding using RE sources to generate electricity and to shift to greener vehicles, leading to a more efficient and low carbon urban system. 


\section{ACKNOWLEDGEMENTS}

The authors express their thanks to the Portuguese Foundation for Science and Technology (FCT) for funding this research through the R\&D COST-TREND project grant PTDC/EGEECO/115815/2009.

\section{REFERENCES}

[1] EC, White paper - roadmap to a single European transport area - towards a competitive and resource efficient transport system, Brussels, 2011.

[2] EC, Green paper - towards a new culture for urban mobility, Brussels, 2007.

[3] EC, Energy 2020 - a strategy for competitive, sustainable and secure energy, 2010.

[4] Banister, D., The Sustainable Mobility Paradigm. Transport Policy, 15, pp. 73-80, 2008. doi: http://dx.doi.org/10.1016/j.tranpol.2007.10.005

[5] IEA, Key World Energy Statistics, International Energy Agency: Paris, 2012. doi: http://dx.doi. org/10.1787/data-00451-en

[6] Newman, P.W.G., Sustainability and cities: extending the metabolism model. Landscape and Urban Planning, 44, pp. 219-226, 1999. doi: http://dx.doi.org/10.1016/s0169-2046(99)00009-2

[7] Sheerin, C., UK material flow accounting. Economic Trends, No. 583, 2002.

[8] Black, W.R, Socio-economic barriers to sustainable transport. Journal of Transport Geography, 8, pp. 141-147, 2000. doi: http://dx.doi.org/10.1016/s0966-6923(99)00038-1

[9] Farla, J., et al., Analysis of Barriers in the transition toward sustainable mobility in Netherlands. Technological Forecasting and Social Change, 77, pp. 1260-1269, 2010. doi: http:// dx.doi.org/10.1016/j.techfore.2010.03.014

[10] Dijk, M., et al., The emergence of an electric mobility trajectory. Energy Policy, 52, pp. 135145, 2013. doi: http://dx.doi.org/10.1016/j.enpol.2012.04.024

[11] Rees, W. \& Wackernagel, M., Urban ecological footprints: why cities cannot be sustainable - and why they are a key to sustainability. Environmental Impact Assessment Review, 16, 223248, 1996. doi: http://dx.doi.org/10.1016/s0195-9255(96)00022-4

[12] Roy, M., Planning for sustainable urbanisation in fast growing cities: mitigation and adaptation issues addressed in Dhaka, Bangladesh. Habitat International, 33, pp. 276-286, 2009. doi: http://dx.doi.org/10.1016/j.habitatint.2008.10.022

[13] Jim, C.Y., Green-space preservation and allocation for sustainable greening of compact cities. Sustainable greening of compact cities. Cities, 21(4), pp. 311-320, 2004. doi: http://dx.doi. org/10.1016/j.cities.2004.04.004

[14] Altes, W.K.K. \& Tambach, M., Municipal strategies for introducing housing on industrial estates as part of compact-city policies in the Netherlands. Cities, 25, pp. 218-229, 2008. doi: http://dx.doi.org/10.1016/j.cities.2008.04.005

[15] Holling, C., Resilience and stability of ecological systems. Annual review of Ecology and Systematics, 4, pp. 1-23, 1973. doi: http://dx.doi.org/10.1146/annurev.es.04.110173.000245

[16] Jabareen, Y., Planning the resilient city: concepts and strategies for coping with climate change and environment risk. Cities, 31, pp. 220-229, 2012. doi: http://dx.doi.org/10.1016/j.cities.2012.05.004

[17] Pickett, S.T.A., et al., Resilient cities: meaning, models, and metaphor for integrating the ecological, socio-economic, and planning realms. Landscape and Urban Planning, 69, pp. 369384, 2004. doi: http://dx.doi.org/10.1016/j.landurbplan.2003.10.035

[18] Shen, L.Y., et al., The application of urban sustainability indicators - a comparison between various practices. Habitat International, 35, pp. 17-29, 2011. doi: http://dx.doi.org/10.1016/j. habitatint.2010.03.006 
[19] Wolman, A., The metabolism of cities. Scientific American, 213, pp. 156-174, 1965. doi: http:// dx.doi.org/10.1038/scientificamerican0965-178

[20] Kennedy, C., et al., The changing metabolism of cities. Journal of Industrial Ecology, 11(2), pp. 43-59, 2007. doi: http://dx.doi.org/10.1162/jie.2007.1107

[21] Gonzalez, A., et al., A decision-support system for sustainable urban metabolism in Europe. Environmental Impact Assessment Review, 38, pp. 109-119, 2013. doi: http://dx.doi. org/10.1016/j.eiar.2012.06.007

[22] Alberti, M., Measuring urban sustainability. Environmental Impact Assessment Review, 16, pp. 381-424, 1996. doi: http://dx.doi.org/10.1016/s0195-9255(96)00083-2

[23] Pincelt, S, et al., An expanded urban metabolism method: toward a system approach for assessing urban energy processes and causes. Landscape and Urban Planning, 107, pp. 193-202, 2012. doi: http://dx.doi.org/10.1016/j.landurbplan.2012.06.006

[24] Ayres, R.U., Industrial ecology: a coming-of-age story. Resources, 130, p. 14, 1989.

[25] Hinterberger, F., et al., Material flow accounting and analysis - a valuable tool for analyses of society-nature interrelationships. Sustainable Europe Research Institute (SERI), Viena, 2003.

[26] Niza, S. et al., Urban metabolism: methodological advances in urban material flow accounting based on the Lisbon case study. Journal of Industrial Ecology, 13(3), pp. 384-405, 2009. doi: http://dx.doi.org/10.1111/j.1530-9290.2009.00130.x

[27] Zonneveld, W., Conceptvorming in de ruimtelijke planning: Encyclopedie van planconcepten [Concept formation in spatial planning: EPC], University of Amsterdam, 1991.

[28] SWOV, Traffic Calming Schemes, Opportunities and Implementation Strategies, Institute for Road Safety Research, Leidschendam, 2003.

[29] TSO, Traffic Calming, Department for Transport, Local Transport Note 1/07, 2007.

[30] Quinet, E. \& Vickerman, R., Principle of Transport Economics, Edward Elgar: Cheltenham, UK, 2004.

[31] Mankiw, N.G., Principles of Microeconomics, 6th edn., Harvard University, South-Western Cengage Learning, Manson, 2012.

[32] Prata, J. \& Andrade-Campos, A., Development of a numerical tool for energy production in water supply systems. First ECCOMAS YIC, Vol. 49, 2012.

[33] Prata, J. \& Lamas, T., Integration of renewable energies in a pleasure boat in the Ria de Aveiro - EcoSunBoat. ESTGV, 2009.

[34] Tchobanouglous, G. et al., Integrated Solid Waste Management. Engineering Principles and Management Issues, McGraw Hill Book Co., Davis, 1993.

[35] CCDR-C, http://datacentro.ccdrc.pt/.

[36] INE, www.ine.pt/.

[37] DGEG, http://www.dgeg.pt/.

[38] PORDATA, http://www.pordata.pt/.

[39] Porter, M., Estratégia Competitiva, Campus, Rio de Janeiro, 1986.

[40] PORTER, M. E. Estratégia Competitiva: Técnicas para análise de indústria e da concorrência Tradução: Elizabeth Maria de Pinho Braga. pp. 22-53. Edição. Rio de Janeiro: Editora Campus, 1991.

[41] Rockfellow, J., Wild cards: preparing for the big one. The Futurist, Jan-Feb, pp. 14-19, 1994.

[42] Prata, J., Arsenio, E. \& Pontes, J.P., Future trends on the costs and benefits of electric, hybrid and conventional vehicles in Europe, 13th WCTR Rio, 2013.

[43] National Education Diabetes Program, Fat and Calorie Counter.

[44] APA, Resíduos Urbanos em 2010, 2011. doi: http://dx.doi.org/10.1590/s1982-45132010000 $\underline{200006}$ 
[45] Prata J., Arsenio, E. \& Pontes, J.P., Moving towards the sustainable city? The role of electric vehicles, renewable energy and energy efficiency. WIT Transactions on Ecology and the Environment, 179, pp. 871-883, 2014. doi: http://dx.doi.org/10.2495/sc130742

[46] Thiel, C., Perujo, A. \& Mercier, A., Cost and $\mathrm{CO}_{2}$ aspects of future vehicle options in Europe under new energy policy scenarios. Energy Policy, 38, pp. 7142-7151, 2010. doi: http://dx.doi. org/10.1016/j.enpol.2010.07.034

[47] ANSR, Vítimas mortais a 30 dias: ano 2011 Aveiro, Autoridade Nacional de Segurança Rodoviária, 2012.

[48] CE/INFRAS/ISI, External costs of Transport in Europe, Update Study for 2008, Delft, 2011.

[49] IMPACT, Handbook on estimation of external costs in the transport sector, Produced within the study Internalisation Measures and Policies for All external Costs of Transport, CE Delft, 2008.

[50] HEATCO, Developing Harmonised European Approaches for Transport Costing and Project Assessment (HEATCO), Deliverable D5, 2006.

[51] EC, External costs: research results on social-environmental damages due to electricity and transport, Brussels, 2003. 